

\title{
A note on the effect of consumer protection requirements on firm strategy
}

Huric Larsen, Jesper Fredborg

February 2014

Online at https://mpra.ub.uni-muenchen.de/58585/

MPRA Paper No. 58585, posted 17 Sep 2014 04:33 UTC 


\title{
A note on the effect of consumer protection requirements on firm strategy (draft)
}

\author{
By \\ Jesper Fredborg Hurić Larsen ${ }^{1}$ \\ University of Southern Denmark \\ Department of Environmental and Business Economics \\ Niels Bohrs Vej 9 \\ DK-6500 Esbjerg \\ Denmark
}

\begin{abstract}
The effect of consumer protection on firms' strategy choices in a market with perfect competition is examined in a simple model. It is found that consumer protection may lead to reduced product quality and adverse effects on firm survival.
\end{abstract}

JEL: B21, L6, L8

Keywords: Strategy, consumer protection, firm incentives

\footnotetext{
${ }^{1}$ Assistant Professor, Markets \& Competition Group, University of Southern Denmark in Esbjerg, Centre for Rural Research, Department of Environmental and Business Economics.
} 


\section{Introduction}

Firms have many different ways of capturing different consumer segments apart from price strategies firms have a whole range of different non-price strategies. Non-price strategies could be something like marketing, corporate social responsibility, focus on quality and product warranties. Non-price strategies can also be imposed on firms by legislation for example consumer protection requirements.

In almost every market in the world consumer rights is protected by law. The purpose of most if not all of these laws is to protect the consumer against unbridled market power of firms and allowing consumers a voice against firms selling a low quality product. In most cases this is argued by policymakers as being of general benefit to markets and consumers as the laws ensure the rights of the consumer and provide incentives for firms to invest in increased quality.

The following analysis is instructive for showing the choices of firms in a market with consumer protection requirements and to examine to what extent the arguments of policymakers are valid.

\section{The model}

A number of firms compete (n-firms) in a market assume that all the firms have the same total cost function $\left(T C_{i}\right)$ of,

$$
T C_{i}=F+\left(c_{p}+c_{q}\right) q_{i}
$$

Where $\mathrm{i}$ indicate firm $\mathrm{i}$ of $\mathrm{n}$ firms in the market, $\mathrm{F}$ is the fixed cost, $c_{p}$ is the marginal cost in relation to the production of the good $\mathrm{q}$ and $c_{q}$ is the marginal cost in relation to the added quality to the product.

Consumer protection implies that a firm is required to replace a broken or faulty unit with a new one without charge. This means that a firm incurs a loss if and whenever the consumer uses the right to change the product. The loss means an increase in a firm's fixed cost as using the right does not affect how the marginal cost of either producing or enhancing the quality of the product.

\section{Implication for the firm}

Assume that the mode of competition in the market best resembles perfect competition allowing a firm no or very limited control on its own pricing. Thus, the optimality condition of the firm requires that $p=M C_{i}=\left(A C_{\min }\right)_{i}$, and since consumer protection will affect a firm's fixed cost we can now compare the price when consumers do not use their right (or do not have the right) and if they do use their right.

If the consumers do not use their right (or do not have the right) the optimal price of the firm is,

$$
p \geq c_{p}+c_{q}=\frac{F+\left(c_{p}+c_{q}\right) q_{i}}{q_{i}} \Leftrightarrow p \geq c_{p}+c_{q}=\frac{F}{q_{i}}+c_{p}+c_{q} \Leftrightarrow p \geq \frac{F}{q_{i}}
$$


The condition simply says that if a firm produces on the market the price in this market must be greater than or equal to the average fixed cost. Since we have not specified a demand curve, we cannot say anything about the market price, but since we have assumed perfect competition, we can say that the market price is fixed and if a firm is producing the market price must be,

$$
p=\frac{F}{q_{i}}+c_{p}+c_{q}
$$

We can use this relation to examine what the effect is of consumer protection on the firm and the strategy choices the firm is facing in the situation if consumers use their right to exchange a faulty product.

As explained above consumer protection does not affect the marginal cost of production or enhancing its quality, but it does affect the firm's fixed cost. Thus, the firm's fixed cost increases to $\bar{F}$. This has the following implication for relation in equation (3),

$$
p<\frac{\bar{F}}{q_{i}}+c_{p}+c_{q}
$$

Thus, relation(4) suggests an imbalance and the following strategy options for the firm to consider:

1. Increase its price to be able to break-even

2. Reduce its production cost if it wants to continue to produce

3. Reduce the quality of its product

4. Quit the market altogether

The first strategy option is not a real possibility given the assumption of the market, but the remaining options are all possibilities.

If a firm cannot reduce its cost of production and do not want to quit the market there is only the possibility of reducing the quality of the product.

\section{Conclusion}

In this simple setup we have showed that consumer protection requirement may have the effect of reducing the overall quality of products. The results also indicate that if the firm is unable to modify and accommodate the consumer protection requirement the firm may exit the market. 


\section{References}

Besanko, D., Dranove, D., Shanley, M., Schaefer, S. (2010). Economics of strategy. John Wiley \& Sons.

Coleff, J. (2012). Can Consumer Complaints Reduce Product Reliability? Paper presented at JEI XXVII. 